\title{
A Roadmap for Institutionalizing Collaborative Care for Depression in a Large Integrated Healthcare System
}

\author{
Karen J. Coleman, $\mathrm{PhD}^{7} \mathrm{D}$, Mark Dreskin, $M D^{2}$, Daniel L. Hackett, MD ${ }^{3}$, \\ Alisa Aunskul, MSHCM${ }^{4}$, Jialuo Liu, MS ${ }^{7}$, Tracy M. Imley, MD ${ }^{5}$, Amy L. Wolfner, MD 6 , and \\ Gabrielle F. Beaubrun, MSHCM ${ }^{7}$
}

\begin{abstract}
'Department of Research and Evaluation, Kaiser Permanente Southern California 100 S. Los Robles, Pasadena, CA, USA; ${ }^{2}$ Department of Family Medicine, Los Angeles Medical Center, Kaiser Permanente Southern California Los Angeles, CA, USA; ${ }^{3}$ Department of Psychiatry, Riverside Medical Center, Kaiser Permanente Southern California Riverside, CA, USA; ${ }^{4}$ Complete Care Support Programs, Kaiser Permanente Southern California Pasadena, CA, USA; ${ }^{5}$ Quality and Clinical Analysis, Kaiser Permanente Southern California Pasadena, CA, USA; ${ }^{6}$ Department of Family Medicine, Invine Medical Center, Kaiser Permanente Southern Californialrvine, CA, USA; ${ }^{7}$ Department of Psychiatry, South Bay Medical Center, Kaiser Permanente Southern California Harbor City, CA, USA.
\end{abstract}

BACKGROUND: Collaborative models for depression have not been widely adopted throughout the USA, possibly because there are no successful roadmaps for implementing these types of models.

OBJECTIVE: To provide such a roadmap through a case study of the institutionalization of a depression care management (DCM) initiative for adult depression in a large healthcare system serving over 300,000 adults with depression.

DESIGN: A retrospective observational program evaluation. Program evaluation results are presented for those patients enrolled in the initiative from January 1, 2015, to December 31, 2018.

PARTICIPANTS: Over a 4-year period, 17,052 patients were treated in the DCM program. In general, participants were women (76\%), were Hispanic (47\%), spoke English $(84 \%)$, and were $51.1 \pm 18.3$ years old, the majority of whom were 30-64 years old (57\%).

INTERVENTION: The collaborative care portion of the DCM initiative (DCM program) was implemented by a collaborative care team containing a treatment specialist, an assessment specialist, administrative staff, a primary care physician, and a psychiatry physician.

MAIN MEASURES: The main outcome measures were total score on the 9-item Patient Health Questionnaire (PHQ-9). Outcomes were improvement (defined as at least $50 \%$ reduction in symptoms) and remission (defined as a PHQ-9 less than 5) of depression symptoms. Follow-up of depression symptoms was also collected at 6 months following discharge.

KEY RESULTS: The average course of treatment in 2018, after full implementation, was $4.6 \pm 3.0$ months; $62 \%$ of patients experienced improvement in symptoms, and $45 \%$ experienced remission of their depression at the time of discharge. These rates were maintained at the 6-month follow-up.

CONCLUSIONS: Collaborative care for depression can be institutionalized in large healthcare systems and be sustained with a specific, detailed roadmap that includes workflows, training, treatment guidelines, and clear

Received September 9, 2019

Accepted July 30, 2020

Published online October 26, 2020 documentation standards that are linked to performance metrics. Extensive stakeholder engagement at every level is also critical for success.

J Gen Intern Med 35(Suppl 2):S839-S48

DOI: $10.1007 / \mathrm{s} 11606-020-06102-8$

(c) Society of General Internal Medicine 2020

\section{INTRODUCTION}

One of the most efficacious/effective approaches to the treatment of depression in healthcare settings is collaborative care. ${ }^{1-17}$ Collaborative care for depression has been tested successfully in randomized trials in primary care, ${ }^{1-6}$ and systematic reviews have shown that it doubled antidepressant adherence, improved depression outcomes lasting 2-5 years, increased patient satisfaction with their care, and increased provider satisfaction with treating depression. ${ }^{7-9}$ Based on this, several organizations have implemented the collaborative care model for depression. ${ }^{10-16}$

In 2012, the Care of Mental, Physical and Substance-use Syndromes (COMPASS) initiative ${ }^{18,19}$ was funded by the Center for Medicare and Medicaid Innovation (CMMI) Health Care Innovation awards ${ }^{20}$ to attempt to institutionalize collaborative care for depression along with the care of conditions such as diabetes. Results from the COMPASS initiative were positive. ${ }^{19}$ Once the COMPASS initiative ended in 2016, participating healthcare systems were expected to use the learnings from its implementation to support and spread the program using institutional resources.

Although a general description of the COMPASS model was published, ${ }^{18,21}$ there was not enough detail provided about the actual process of implementation to easily replicate in other healthcare systems attempting to institutionalize the care of depression in primary care settings. This lack of detail, which is also seen generally in the literature reporting the effects of collaborative care, ${ }^{22-25}$ may be responsible for the limited uptake of collaborative care models for depression throughout the USA. 
Kaiser Permanente Southern California (KPSC) was one of the healthcare systems participating in the COMPASS initiative. In 2016, once COMPASS ended, KPSC chose to focus on mild-to-moderate depression in adult primary care only and implemented the depression care management (DCM) initiative. The initiative addressed the continuum of care through diagnosis, treatment, and monitoring for recurrence. KPSC chose to focus on a single condition because this was more aligned with the existing institutional practice of providing infrastructure and staff support for specific conditions (i.e., diabetes). The current study describes the process used to institutionalize and internally support collaborative care for depression in a large, complex integrated healthcare system using the learnings from the COMPASS initiative.

\section{METHODS}

\section{Participants and Setting}

KPSC is a large integrated healthcare system that serves 4.2 million children, adolescents, and adults in the southern half of the state of California. It owns 14 hospitals (which have defined service areas) and 209 medical office buildings and has a practice of 6000 primary and specialty care physicians. Figure 1 provides a map outlining the 14 service areas of KPSC each of which had a local KPSC DCM team delivering the DCM program and assisting with other aspects of the DCM initiative. Patients eligible for the present study were treated in the KPSC DCM program during the period of January 1, 2015-December 31, 2018. Eligibility for the program was having a 9-item Patient Health Questionnaire (PHQ9) total score of 10-19, being an adult 18 years and older, being an active member of the health plan at the time of enrollment, and being willing to engage in at least 3 months of treatment with at least one in-person visit and two additional telephonic/in-person visits. A diagnosis of depression was not required for enrollment.

Exclusions were having an active substance use disorder or eating disorder, serious mental illness, having anxiety as the primary mood disorder, personality disorders, suicidal ideation with intent, cognitive impairment and/or diagnosis of dementia, and any other conditions that would make it difficult to effectively participate in treatment for mild to moderate depression. In addition, treatment teams could exclude patients who were being actively seen in psychiatry and/or addiction medicine if they felt that the DCM program would not benefit the patient. However, teams were encouraged to work with psychiatry to co-manage patients instead of automatically excluding them as the program was designed to assist psychiatry with access to care burdens. As of April 1, 2019, there were 307,835 adult patients 18 years and older diagnosed with depression, with an estimated $40 \%(n=123,134)$ eligible for DCM program services based solely upon a PHQ-9 total score of 10-19. Approval for this study was obtained

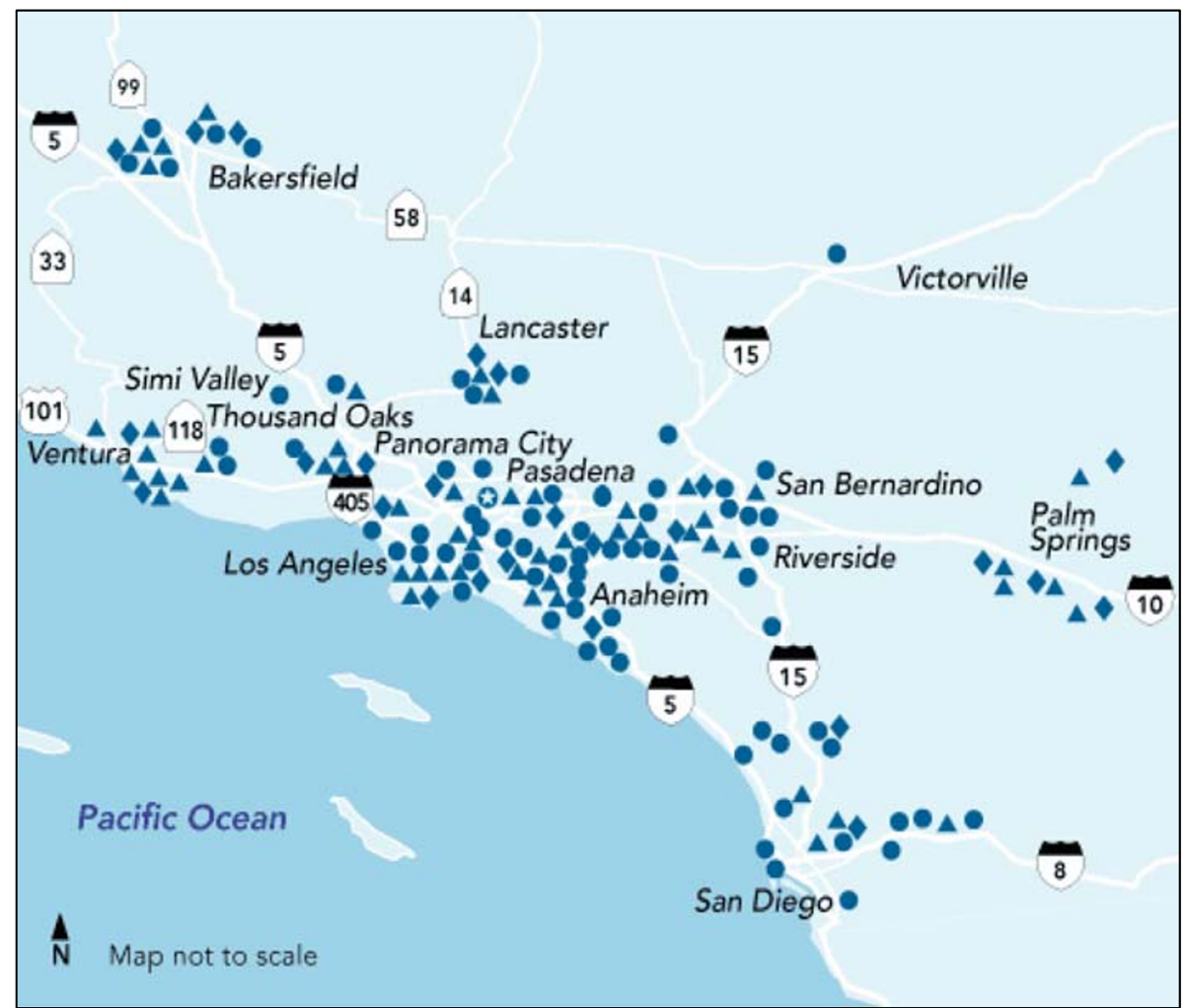

Fig. 1 Map of the Kaiser Permanente Southern California (KPSC) region with hospitals (diamonds) which define the medical center service regions, medical office buildings (circles), and other facilities (triangles). 
from the KPSC Institutional Review Board (IRB) for Human Subjects.

\section{Implementation}

Program Goals and Initial DCM Initiative Design. There were three main goals for the KPSC DCM initiative: (1) to prepare the adult primary care departments of the healthcare system (family medicine and internal medicine) to systematically use an evidence-based standard to identify, diagnose, and treat depression in preparation for the requirements from the National Committee for Quality Assurance (NCQA; please see next section for an explanation of these requirements); ${ }^{26}$

(2) to scale the collaborative model of care for patients with depression to a population approach; and (3) to provide support for the Departments of Behavioral Health, Family Medicine, and Internal Medicine to increase access to care for patients with mild to moderate depression.

The KPSC DCM initiative that was first tested and further refined included the following five main elements: (1) an education and mentoring program for primary care physicians to identify, diagnose, and treat depression using the PHQ- $9^{27}$ as well as how to refer to and work with the DCM team in their service region; (2) a DCM team that treated patients in the DCM program; (3) a standardized administrative oversight structure in the Department of Complete Care with a department administrator who oversaw the operations of the initiative; (4) an electronic patient care registry used for panel management and performance metrics; and (5) an extensive set of process and outcome measures and goals which were monitored by the organizational leadership team.

The DCM team itself consisted of (1) a treatment specialist (licensed clinical social worker or a nurse practitioner/physician's assistant) who treated patients; (2) an assessment specialist (registered nurse, medical assistant, or a licensed clinical social worker) who received program referrals, screened patients for eligibility, and coordinated enrollment in the DCM with the treatment specialist; (3) an administrative/project management support staff who scheduled appointments, followed-up on patients to administer the PHQ-9 required for monitoring treatment response, and prepared patients for systematic case review using the electronic patient care registry; and (4) at least one primary care physician and psychiatrist champion who supported the teams with systematic case review, interfacing with their respective departments, and assisting the DCM teams with treatment decisions. The remaining sections of the methods describe how the DCM initiative was created, tested, and refined.

Evidence-Based Standard. Initially, while participating in the COMPASS trial, the DCM program was required to have certain components that have been described in detail elsewhere. ${ }^{18,}{ }^{19}$ In addition to the work on COMPASS, the DCM initiative was designed to be responsive to the NCQA's Healthcare Effectiveness Data and Information Set (HEDIS) measures for depression monitoring that began in 2016 which recommended the use of the PHQ-9 as the instrument to monitor symptoms of depression. ${ }^{26}$

Overview of Implementation Approach. The KPSC DCM initiative began in 1999 as a site in the Improving Mood-Promoting Access to Collaborative Treatment (IMPACT) randomized trial to treat older adults patients with depression in primary care settings. ${ }^{17}$ After the trial was completed, the program continued; however, it was primarily maintained as a depression screening and referral program for patients with cardiovascular disease. Near the completion of the COMPASS trial (January 1, 2015), KPSC began the process of using the learnings from the trial to change how depression was treated in primary care settings. Figure 2 outlines the KPSC DCM initiative implementation model. In general, the steps in this model follow the Veterans Affairs' Quality Enhancement Research Initiative (VA QUERI) approach of having the research team provide guidance in evidence-based approaches to the stakeholders. ${ }^{28,} 29$ This meant that the research and administrative team involved in COMPASS began the first step (recruiting stakeholders) by presenting key stakeholders with a tentative plan for targeted policies, environments, and behaviors.

A foundational element of this model was the process developed by the Institute for Healthcare Improvement (IHI) for rapid improvement in healthcare systems. ${ }^{30,31}$ There are several elements from the rapid improvement process that are uniquely suited to institutionalizing the care of patients with depression in primary care settings: (1) capacity building within the organization to adapt evidence-based interventions to address organizational concerns (rather than relying on research staff to implement), (2) fostering ownership and sustainability as part of every step in the process of change, (3) providing several temporary Plan-Do-Study-Act (PDSA) learning cycles for people to "try out" change without committing large amounts of organizational resources for long periods of time, and (4) allowing for incremental and dynamic change in that goals are revisited depending upon the feedback from the PDSA learning cycles. Another added advantage of this implementation approach is that data collection is essential to the process of change, helping the organization see the value of research as an inherent activity for capacity building. The research team becomes a partner in and an asset for organizational development rather than one more outside force to contend with when trying to make decisions.

Step 1: Recruit Stakeholders. A diverse group of stakeholders were necessary for implementation. These included obvious groups such as the healthcare system leadership who would approve and oversee the funding of the expansion of the program, primary care providers and psychiatrists, and staff in the DCM program itself. During implementation, we also found that other 


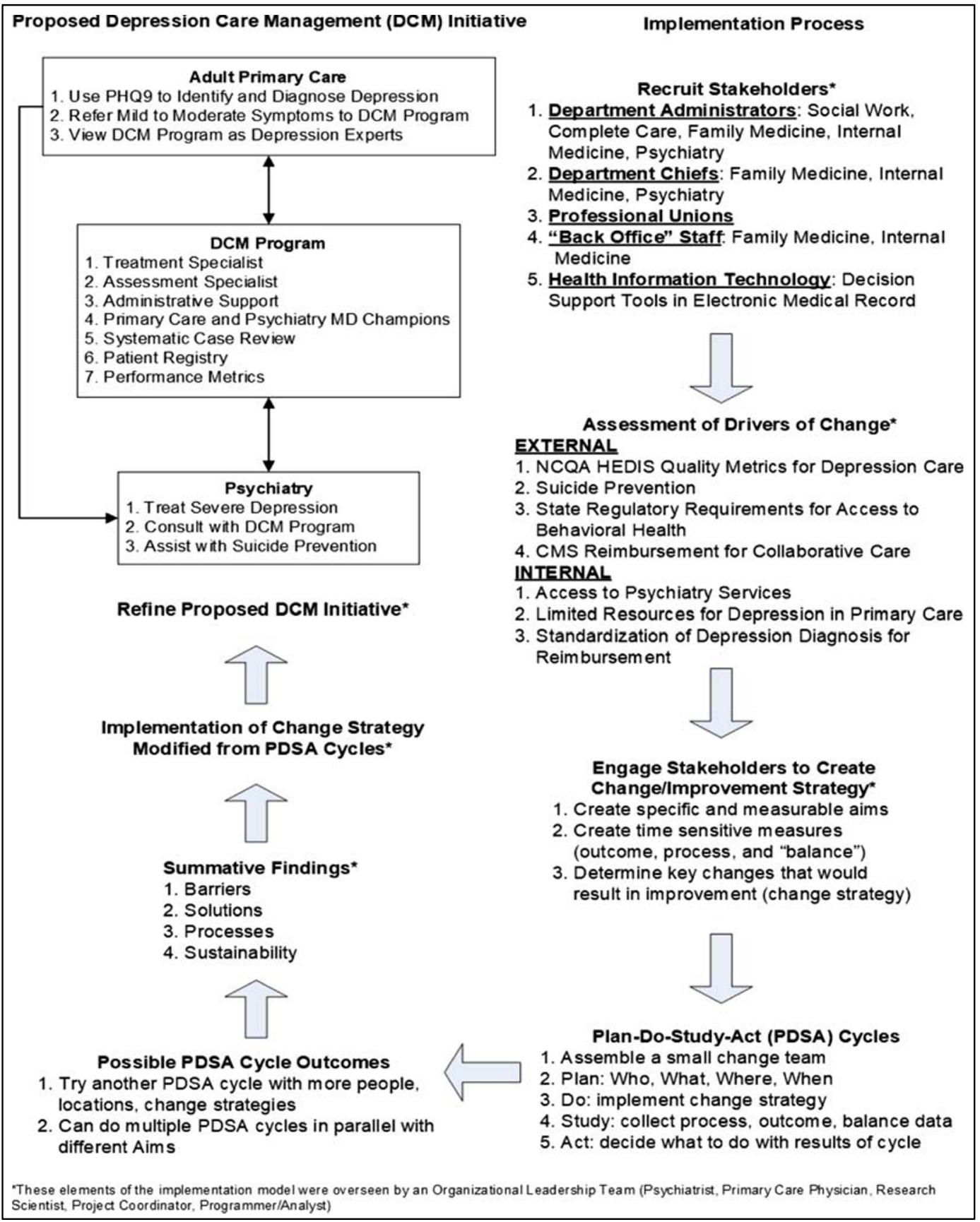

Fig. 2 The Kaiser Permanente Southern California (KPSC) Depression Care Management (DCM) initiative implementation model. In general, the steps in this model follow the Veterans Affairs' Quality Enhancement Research Initiative (VA QUERI) and the Institute for Healthcare Improvement's (IHI) approaches. ${ }^{28-31}$

stakeholders were critical to the success of the program. These included department administrators who controlled the operations of family and internal medicine, behavioral health, social medicine, and complete care. Complete care is a free-standing department under which all care management programs are administered at KPSC. These department administrators oversaw the work of several staff who were instrumental in developing workflows and processes critical to the success of the DCM initiative. These staff included nurses, social workers, medical assistants, project managers, and clerical staff that handled operational tasks such as scheduling and checking patients in for their appointments.

Step 2: Organizational Readiness and Drivers. The Consolidated Framework for Implementation Research $(\mathrm{CFIR})^{32}$ is helpful in conceptualizing the internal and external environmental factors that provided the drivers for 
change at KPSC. One very large external driver was the NCQA HEDIS metrics mentioned previously related to depression. ${ }^{26}$ Briefly, these are standardized metrics that are used to compare hospitals' and healthcare systems' quality of care so that purchasers (individuals, employers, and government) can make decisions about which systems/ hospitals to approve for insurance coverage. We argued that the DCM initiative would help the healthcare system improve their depression-related quality metrics related to screening for and treatment of depression. A major internal driver was the limited access to behavioral healthcare services. Much of the availability for behavioral healthcare was used for mild to moderate depression limiting access for more serious mental illness such as severe depression and bipolar disorder. Because collaborative care for depression had a long-standing evidence base for successful treatment of mild to moderate depression, we argued that the DCM initiative could divert these patients away from psychiatry and improve access for more severe depression and other mental health conditions.

Step 3: Engage Stakeholders to Create Strategy. A healthcare system-wide leadership team (organizational leadership team) was formed to include representation from the major department stakeholders in the process: adult primary care, psychiatry, and complete care. A research scientist was also part of this team with content expertise in mental health treatment and implementation research and also a full-time project manager dedicated to the implementation of the DCM initiative. At each of the 14 medical center service regions, there was a local change team of stakeholders who were called champions (referred to as MD consultants in the IMPACT and COMPASS models). This included a primary care physician, a psychiatrist, and a complete care department administrator. In addition to these members, all staff involved with the existing DCM program were also part of this team. Other stakeholders were part of these local teams as needed including department administrators of social medicine and licensed clinical social workers. Site visits from the organizational leadership team to each of the 14 local change teams were critical to gathering stakeholder feedback throughout the PDSA cycles described below.

Step 4: Piloting Changes with PDSA Cycles. There were literally dozens of PDSA cycles throughout this process, all of which happened locally. Four of the 14 KPSC service areas were part of the COMPASS initiative and were used primarily for piloting change; however, other local change teams were also engaged in redesigning their programs to meet the goals of the DCM initiative (please see the previous "Program Goals and Initial DCM Initiative Design" section of the methods). Two main PDSA efforts that were conducted by all change teams were (1) using the PHQ-9 in adult primary care to diagnose depression and make treatment decisions and (2) adding an administrative/project management support staff into the DCM program to offload administrative work from the treatment specialists who were refocused solely on providing care.

Step 5a: Adjustment of Initiative Based on PDSA Cycles: PHQ-9. The PHQ-9 administration PDSA cycles provided a great deal of insight into the diagnosis and treatment of depression in primary care settings. These insights included the fact that most primary care physicians learned to diagnose depression in medical school using their own assessment tool, the SIG-E-CAPS, ${ }^{33}$ which was a mnemonic device to remember the symptoms of depression: sleep, interest, guilt, energy, concentration, appetite, psychomotor, and suicide. Physicians had "smart phrases" they had created in the electronic medical record to capture the responses to SIG-E-CAPS, and they did not understand why we could not use these responses for the DCM initiative. In addition, there was concern that this new process and instrument would take too much time in an already overburdened appointment and that only clinical staff with specific mental health training could administer the assessment because it asked about suicidal ideation. Primary care physicians and administrative leadership of primary care departments were concerned that the physicians could be held personally responsible for ideation that was not immediately addressed.

Eventually, a process where a patient would receive a paper-based PHQ-9 which was then entered into the electronic medical record was implemented and a performance metric was created to monitor the process (please see the "Surveillance" section below for a description of the performance metrics). Because we wanted physicians to use the PHQ-9 while making diagnosis and treatment decisions, the performance metric was based on administering the PHQ-9 to all patients newly diagnosed with depression in adult primary care. Patients who came in for either a scheduled in person appointment or a same day/walk in appointment could be given a PHQ-9 if they had (1) a reason for visit/chief complaint of depression and/or symptoms related to depression such as insomnia, pain, low energy, and loss of appetite and/or (2) a mention of depression and/or these symptoms during check-in, vitals check, or the actual visit. An appointment clerk could give the PHQ-9 at check-in, or a medical assistant/nurse could give the PHQ-9 when doing the vitals, or a nurse could give the PHQ-9 during the visit as directed by the primary care physician. Any primary care team member could enter the PHQ-9 into the electronic medical record and the physician would review the results and discuss with the patients. We encouraged the teams to think of the PHQ-9 like any other test to assist with diagnosis such as a urinalysis, blood draw, and X-ray. In addition, the PHQ-9 was designed to be self-administered ${ }^{27}$ so a clinical staff member did not need to administer the PHQ-9. 
Step 5b: Adjustment of Initiative Based on PDSA Cycles: Administrative/Project Staff for DCM Program. During the COMPASS initiative, it became clear that scaling the DCM program up to a population care strategy would necessitate non-clinical support staff to assist with follow-up assessment, appointment scheduling, preparing patients for systematic case review, and other tasks. Clinical teams had many concerns, similar to the primary care teams, that non-clinical staff could not talk to patients about depression symptoms. Therefore, the pilot sites developed a protocol for non-clinical staff to call patients to administer PHQ-9s, call or email for appointment reminders, and prepare patients for systematic case review using the electronic patient registry. Oversight was provided by the department administrators, and clinical staff who were part of the DCM program were always available to address staff concerns while outreaching patients.

Step 6: Institutionalization. Institutionalization involved using the results from the PDSA cycles, the initiative process and outcome measures (please see the "Surveillance" section below for a description of the performance metrics and Table 1), specific time allocation per patient which was used to determine the patient load for the DCM team member providing treatment, and a proposed detailed workflow to prepare a business case for the DCM initiative (please see Fig. 3). The business case was accepted to financially support a DCM program team in every one of the 14 medical center service regions which consisted of a treatment specialist (licensed clinical social worker or a nurse practitioner/physician's assistant), an assessment specialist (registered nurse, medical assistant, or a licensed clinical social worker), and an administrative/project management support staff. In addition to financial support from the organization, leadership and oversight for the program consolidated into the departments of complete care at each of the 14 medical center service regions.

\section{Surveillance}

The KPSC DCM initiative had an electronic patient registry and an electronic scorecard that had process and outcome metrics directly related to the goals of the initiative. The goals were set by the organizational leadership team with input from the stakeholders in steps 1 and 3 of the VA QUERI model (see Fig. 2) and are presented in Table 1. The metrics used to address these goals are also presented in Table 2. The patient registry displayed the following information for every patient enrolled in treatment every 24-48 h: medical record number, name, address, phone number, email, preferred language, gender, treatment specialist, enrollment date, PHQ-9 total score at enrollment, months in the program, days since last treatment specialist contact, days since last PHQ-9, last two PHQ-9 total scores, diagnosis, primary care physician and location, date for next appointment scheduled, and date for next PHQ-9.
Table 1 Goals and Metrics for the Kaiser Permanente Southern California (KPSC) Depression Care Management (DCM) Initiative

\begin{tabular}{|c|c|c|}
\hline$\overline{\text { Goal }}$ & $\begin{array}{l}\text { Metric } \\
\text { numerator }\end{array}$ & $\begin{array}{l}\text { Metric } \\
\text { denominator }\end{array}$ \\
\hline $\begin{array}{l}\text { Use the PHQ-9 when diagnos- } \\
\text { ing patients with a first/new } \\
\text { episode of depression } \\
\text { (Goal>=50\%) }\end{array}$ & $\begin{array}{l}\text { No. of patients } \\
\text { with first/new } \\
\text { episode of de- } \\
\text { pression and a } \\
\text { PHQ-9 }\end{array}$ & $\begin{array}{l}\text { No. of patients } \\
\text { with first/new } \\
\text { episode of de- } \\
\text { pression }\end{array}$ \\
\hline
\end{tabular}

Enroll patients with a first/new episode of depression with PHQ-9 $10-19$ in the DCM program (Goals $>=50 \%)$

Panel size at any time in active treatment in the DCM program per full-time treatment specialist (Goal $>=120$ ) Patients in active treatment who are engaged (panel size $x$ PHQ-9 administration rate in treatment) (Goal $>=96$ [120*80\%])

Administer PHQ-9 for patients in active treatment every month (Goal $>=80 \%$ )

Outreach patients in active treatment every month (contact attempt) (Goal>=95\%)

Average months in treatment after discharge (Goal=3-6 months)

Patients achieving remission $($ Goal $>=25 \%)$

Patients achieving improvement (Goal>=50\%)

Administer a follow-up PHQ-9 6 months after discharge (Goal>=70\%)
No. of patients with first/new episode of depression and PHQ-9 10-19 enrolled in treatment 120

96

No. of patients in active treatment with a PHQ-9 for the reporting month No. of patients in active treatment with a telephone or inperson visit scheduled for the reporting month

3-6 months

\section{Patients}

discharged

from at least 3

months of

treatment with

an enrollment

PHQ-9 total

score 10+

whose last

PHQ-9 total

score $<5$

Patients

discharged

months of

treatment with

an enrollment

PHQ-9 total

score $10+$

whose last

PHQ-9 total

score $\geq 50 \%$

lower than en-

rollment PHQ-9

total score

Patients

discharged

from treatment

$<12$ months

from reporting

date with a

PHQ-9 total

score between 4

and 8 months

after discharge from at least 3
No. of patients in active treatment

No. of patients in active treatment

Patients

discharged from at least 3 months of treatment with an enrollment PHQ-9 total score $10+$

Patients

discharged from at least 3 months of treatment with an enrollment PHQ-9 total score $10+$

Patients discharged from treatment $<12$ months from reporting date 


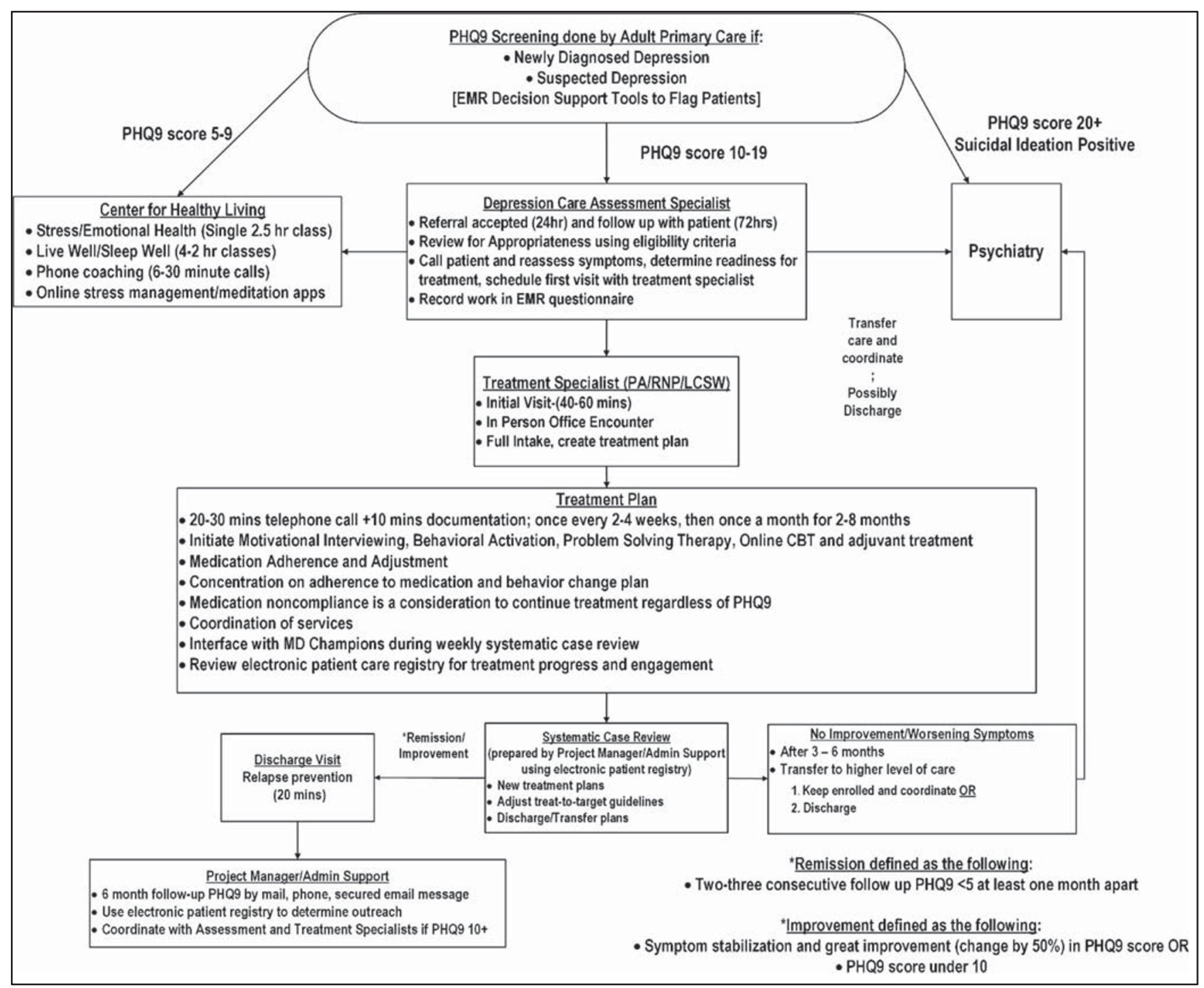

Fig. 3 Workflow presenting the Kaiser Permanente Southern California (KPSC) Depression Care Management (DCM) initiative.

\section{Analyses}

Descriptive statistics were calculated using means and standard deviations for continuous variables and counts and frequencies for categorical variables. Changes in categorical metrics from 1 year to another were analyzed using the chisquare statistic. To compare change in depression symptoms from baseline to the end of program and the 6-month followup, data were collapsed across years and PHQ-9 total scores were analyzed using one-sample $t$ tests, while remission and relapse rates were compared using the chi-square statistic. All analyses were done in SPSS (version 26.0, IBM Corp.). During the PDSA cycles, there were numerous administrative meetings with the clinical teams to discuss barriers and facilitators for implementation. This information was used as the basis of the recommendations for other healthcare systems in the discussion.
Depression symptom improvement was defined as having at least a $50 \%$ reduction in the PHQ-9 total score at discharge compared with the enrollment total score. ${ }^{26,34}$ Depression symptom remission was defined as having a PHQ-9 total score at discharge $<5 .{ }^{26,34}$ Only patients with a PHQ-9 total score of $10+$ who were discharged after at least 3 months of treatment were considered for improvement and discharge outcomes. Engagement in treatment was defined as patients who had at least two PHQ-9 assessments following the enrollment PHQ-9 for at least 3 months of treatment (at least three PHQ-9 measures in total). The engagement metric was based on the initiative goal of having patients in treatment for at least 3 months with a PHQ-9 in each month after enrollment (see Table 1); thus, all patients engaged in treatment had a minimum of three assessments. 
Table 2 Demographics and Outcomes for Collaborative Care for the Kaiser Permanente Southern California (KPSC) Depression Care Management (DCM) Initiative Across Time

\begin{tabular}{|c|c|c|c|c|}
\hline & 2015 & 2016 & 2017 & 2018 \\
\hline $\begin{array}{l}\text { Patients newly diagnosed with depression (NDD) in adult primary } \\
\text { care (APC) }\end{array}$ & 45,535 & 56,641 & 63,843 & 71,257 \\
\hline Patients NDD in APC with PHQ-9, \%(n) & $10.7(4871)$ & $18.0(10,221)$ & $37.1(23,691)$ & $50.9(36,307)$ \\
\hline Referrals to psychiatry for patients NDD, \% (n) & $5.7(2598)$ & $5.5(3100)$ & $6.4(4077)$ & $7.5(5323)$ \\
\hline $\begin{array}{l}\text { Patients NDD in APC with PHQ-9 total score 10-19 (eligible for } \\
\text { DCM program) }\end{array}$ & 2650 & 5195 & 11,373 & 16,304 \\
\hline Patients enrolled in the DCM program $(n)$ & 3270 & 3751 & 4826 & 5205 \\
\hline Women, \% (n) & $73(2376)$ & $72(2711)$ & $76(3642)$ & $76(3979)$ \\
\hline \multicolumn{5}{|l|}{ Race/ethnicity, \% (n) } \\
\hline Hispanic & $51(1660)$ & $45(1702)$ & $44(2108)$ & $47(2427)$ \\
\hline White & $33(1071)$ & 36 (1349) & $36(1756)$ & $34(1766)$ \\
\hline Black & $9(278)$ & $10(388)$ & $11(533)$ & $10(539)$ \\
\hline Asian & $5(174)$ & $5(187)$ & $5(255)$ & $4(217)$ \\
\hline Other & $3(87)$ & $3(125)$ & $4(174)$ & $5(256)$ \\
\hline \multicolumn{5}{|l|}{ Language spoken, $\%(n)$} \\
\hline English & $79(2591)$ & $81(3033)$ & $85(4110)$ & $84(4375)$ \\
\hline Spanish & $20(655)$ & $18 \%(686)$ & $14(686)$ & $15(810)$ \\
\hline Other & $1(24)$ & $1(32)$ & $1(30)$ & $1(20)$ \\
\hline Age (years) & $56.3 \pm 16.8$ & $54.8 \pm 17.5$ & $53.6 \pm 17.8$ & $51.1 \pm 18.3$ \\
\hline $18-29, \%(n)$ & $7(243)$ & $10(390)$ & $12(568)$ & $16(819)$ \\
\hline $30-64, \%(n)$ & $58(1907)$ & 59 (2213) & $58(2810)$ & $57(2985)$ \\
\hline $65+, \%(n)$ & $34(1120)$ & $31(1148)$ & 30 (1448) & $27(1401)$ \\
\hline PHQ-9 total score at enrollment & $12 \pm 6$ & $12 \pm 5$ & $13 \pm 5$ & $13 \pm 4$ \\
\hline PHQ-9 <5, \% (n) & $14(458)$ & $7(275)$ & $3(127)$ & $3(141)$ \\
\hline PHQ-9 5-9, \% (n) & $8(249)$ & $18(682)$ & $19(896)$ & $13(697)$ \\
\hline PHQ-9 10-19, \% (n) & $71(2307)$ & $67(2526)$ & $71(3434)$ & 78 (4064) \\
\hline PHQ-9 20+, \% (n) & $8(256)$ & $7(268)$ & $8(369)$ & $6(303)$ \\
\hline Months of treatment for discharged patients & $\begin{array}{l}5.1 \pm 6.7[n= \\
3213]\end{array}$ & $\begin{array}{l}5.6 \pm 6.9[n= \\
3741]\end{array}$ & $\begin{array}{l}5.3 \pm 4.2[n= \\
4787]\end{array}$ & $\begin{array}{l}4.6 \pm 3.0[n= \\
4920]\end{array}$ \\
\hline$<1, \%(n)$ & $21(668)$ & $15(578)$ & $6(269)$ & $6(272)$ \\
\hline $1-3, \%(n)$ & 36 (1153) & $33(1222)$ & $29(1370)$ & $30(1455)$ \\
\hline $3-6, \%(n)$ & $17(547)$ & $23(868)$ & $33(1570)$ & $38(1878)$ \\
\hline $6-12, \%(n)$ & $15(466)$ & $16(600)$ & $25(1190)$ & $24(1189)$ \\
\hline $12+, \%(n)$ & $12(379)$ & $13(473)$ & $8(388)$ & $3(126)$ \\
\hline Patients taking antidepressants during the DCM program, $\%(n)$ & $56.0(1830)$ & $59.2(2221)$ & $60.4(2913)$ & $59.6(3103)$ \\
\hline Patients engaged while in the DCM program*, \% $(n)$ & $41.8(1370)$ & $54.4(2040)$ & $69.0(3333)$ & $73.7(3837)$ \\
\hline $\begin{array}{l}\text { Depression symptom improvement }{ }^{\dagger} \text { at discharge from DCM } \\
\text { program, \% }(n)\end{array}$ & $\begin{array}{l}54(592)[n= \\
1101]\end{array}$ & $\begin{array}{l}55(848)[n= \\
1548]\end{array}$ & $\begin{array}{l}56(1397)[n= \\
2490]\end{array}$ & $\begin{array}{l}62(1678)[n= \\
2727]\end{array}$ \\
\hline $\begin{array}{l}\text { Depression symptom remission }{ }^{*} \text { at discharge from the DCM } \\
\text { program, } \%(n)\end{array}$ & $\begin{array}{l}37(411)[n= \\
1101]\end{array}$ & $\begin{array}{l}38(596)[n= \\
1548]\end{array}$ & $\begin{array}{l}41(1033)[n= \\
2490]\end{array}$ & $\begin{array}{l}45(1235)[n= \\
2727]\end{array}$ \\
\hline $\begin{array}{l}\text { Depression symptom improvement }{ }^{\dagger} \text { at } 6 \text { months after discharge from } \\
\text { the DCM program, \% }(n)\end{array}$ & $\begin{array}{l}70(138)[n= \\
197]\end{array}$ & $\begin{array}{l}59(297)[n= \\
505]\end{array}$ & $\begin{array}{l}61(777)[n= \\
1276]\end{array}$ & $\begin{array}{l}61(693)[n= \\
1132]\end{array}$ \\
\hline $\begin{array}{l}\text { Depression symptom remission }{ }^{5} \text { at } 6 \text { months after discharge from the } \\
\text { DCM program, } \%(n)\end{array}$ & $\begin{array}{l}56(110)[n= \\
197]\end{array}$ & $\begin{array}{l}43(218)[n= \\
505]\end{array}$ & $\begin{array}{l}48(615)[n= \\
1276]\end{array}$ & $\begin{array}{l}47(536)[n= \\
1132]\end{array}$ \\
\hline
\end{tabular}

*Engagement in treatment was defined as patients who had at least two PHQ-9 assessments following the enrollment PHQ-9 for at least 3 months of treatment (at least three PHQ-9 measures in total) $\dagger$ Depression symptom improvement was defined as having at least a 50\% reduction in the PHQ-9 total score at discharge compared with the enrollment total score. Only patients with a PHQ-9 total score of 10+ who were discharged after at least 3 months of treatment were considered for improvement outcomes

$\neq$ Depression symptom remission was defined as having a PHQ-9 total score at discharge $<5$. Only patients with a PHQ-9 total score of $10+$ who were discharged after at least 3 months of treatment were considered for improvement outcomes

\section{RESULTS}

\section{Participants}

The characteristics of patient treated in the KPSC DCM program from January 1, 2015, to December 31, 2018, are shown in Table 2. A total of 17,052 patients were treated in the KPSC DCM program over this time period. Descriptive statistics are summarized for 2018. In general, participants were women (76\%), were Hispanic (47\%), spoke English (84\%), and were $51.1 \pm 18.3$ years old the majority of whom were 30-64 years old $(57 \%)$. Most patients in the program had mild-tomoderate depression symptoms $(78 \%)$ at the time of enrollment and spent an average of $4.6 \pm 3.0$ months in treatment; most of whom were in treatment for between 1 and 6 months (48\%). Over half were taking antidepressants during treatment $(59.6 \%)$, and $73.7 \%$ were engaged in treatment.

\section{Effectiveness}

Each year of the program, the PHQ-9 was used more frequently with patients being diagnosed with their first or a new episode of depression (10.7\% in 2015 to $50.9 \%$ in 2018). Referrals for patients newly diagnosed with depression to psychiatry from adult primary care increased each year from $5.7 \%$ in 2015 to $7.5 \%$. This was a relatively small increase compared with the increase in the number of PHQ9 assessments (increase by a factor of 1.3 compared to PHQ-9 rates increasing by a factor of 4.76). A total of 17,052 patients were treated in the DCM program with 
numbers increasing every year (from 2650 in 2015 to 5323 in 2018).

Even with increasing numbers of patients, treatment outcomes continued to significantly improve with $37 \%$ of patients achieving remission of their depression symptoms in 2015 to $45 \%$ in $2018\left(X^{2}(4)=209.08 ; p<.001\right)$. Improvement rates also increased significantly from $54 \%$ in 2015 to $62 \%$ in 2018 $\left(X^{2}(4)=402.85 ; p<.001\right)$. Engagement rates while in treatment also significantly increased during this same time period from $41.8 \%$ in 2015 to $73.7 \%$ in $2018\left(X^{2}(4)=1003.97 ; p<\right.$ $.001)$. The average months of treatment were constant from $5.1 \pm 6.7$ months in 2015 to $4.6 \pm 3.0$ months in 2018. Across all years of the DCM program, there was a significant decrease in PHQ-9 total score from enrollment to the end of treatment $(14.6 \pm 3.4$ to $7.2 \pm 6.1 ; t(8,421)=105.93 ; p<.001)$ and from enrollment to the 6-month follow-up $(14.7 \pm 3.4$ vs $6.9 \pm 6.6$; $t(3,112)=62.41 ; p<.001)$, with a small significant increase from the end of treatment to the 6-month follow-up ( $6.7 \pm 6.2$ vs $6.9 \pm 6.6 ; t(3,112)=-2.28 ; p=.02)$.

\section{DISCUSSION}

The KPSC DCM initiative was successfully implemented to change adult primary care practice for identifying, diagnosing, and treating depression in a large healthcare system serving over 300,000 patients with depression. By the end of 2018, 51\% of all patients with a new diagnosis for depression had received a PHQ-9 ( $n=$ 36,307 ) and over 17,000 patients had been treated in the DCM program. Results were better than those reported in previous tests of collaborative care with $62 \%$ of patients experiencing improvement and $45 \%$ remission in 2018. ${ }^{1-9}, 18,19$ These results were maintained 6 months following the end of treatment with $61 \%$ improvement and $47 \%$ remission. Some key aspects of the success of this institutionalization were (1) the importance of meaningful, sustained stakeholder engagement at all levels of implementation; (2) understanding and using external and internal drivers of organizational behavior to make change (3) a full-time project manager for the initiative that also directs the work of an organizational leadership team; (4) electronic population management tools for patient care and reporting; (5) creation of shared initiative goals that meet stakeholder priorities; and (6) strong commitment to the use of rapid improvement cycles to try process changes before mandating their use organization-wide.

To begin a program like the KPSC DCM initiative, we recommend a part-time electronic medical record programmer who can build and maintain a patient registry for the program as well as produce simple quality metrics monitoring its implementation, a full-time midlevel provider (nurse practitioner or physician's assistant) with training in psychiatric practice as the treatment care manager with the ability to prescribe medication, and a full-time administrative support/ project manager position who is responsible for managing the patient registry, organizing systematic case review, following up on patients, and interacting with primary care teams to insure the right patients are reaching the program. In addition, primary care and psychiatry MD champions need release time to conduct systematic case review weekly to assist the care manager with treatment decisions. This team could treat 360 patients per year with an average treatment length of 4 months.

There are several limitations to the evaluation of the institutionalization of the KPSC DCM initiative that should be considered when interpreting the outcomes. One is that there was no control group for comparison. It is well known that depression symptoms can resolve on their own, although this is unlikely in true depression. ${ }^{34}$ Without a control group that did not receive treatment in the DCM program, it is difficult to determine conclusively that the DCM program was the sole reason for depression symptom improvement and remission.

Another limitation with the KPSC DCM initiative is that it may not be generalizable to other healthcare settings that do not provide integrated care, have electronic medical records, or already have infrastructure from previous research trials on which to build a program. Although the last point is surmountable, without integration or electronic medical records with decision aids and registry creation possibilities, it would be difficult to institutionalize an initiative like the KPSC DCM. However, KPSC represents the future of healthcare as systems move towards the integrated medical care and electronic medical and billing record systems that are required by the Affordable Care Act.

Finally, there are limitations of the PHQ-9 for diagnosis and monitoring of depression symptoms. ${ }^{35}$ However, the NCQA's HEDIS measures for depression monitoring that began in 2016 recommended the use of the PHQ-9 as the instrument to monitor symptoms of depression. ${ }^{26}$ In addition, the PHQ-9 was built into the electronic medical record when we began the KPSC DCM initiative and thus we chose to use the PHQ-9 for the program in spite of its limitations.

Collaborative care for depression can be institutionalized in large healthcare systems and be sustained with a specific, detailed roadmap that includes workflows, training, treatment guidelines, and clear documentation standards that are linked to performance metrics. Extensive stakeholder engagement at every level is also critical for success.

Acknowledgments: Parts of this evaluation were presented at the National American Heart Association scientific sessions in Anaheim, CA, on November 12, 2017, and at the National Kaiser Permanente Guality Conference in Oakland, CA, on June 20, 2018.

Corresponding Author: Karen J. Coleman, PhD; Department of Research and Evaluation, Kaiser Permanente Southern California 100 S. Los Robles, Pasadena, CA 91104, USA (e-mail: Karen.J. Coleman@kp.org). 
Funding Information Funding for this study was provided by the Southern California Permanente Medical Group.

\section{Compliance with Ethical Standards:}

Conflict of Interest: The authors declare that they do not have a conflict of interest.

\section{REFERENCES}

1. Katzelnick DJ, Von Korff M, Chung H, Provost LP, Wagner EH. Applying depression-specific change concepts in a collaborative breakthrough series. Joint Commiss J Qual Patient Safety/Joint Commiss Resour 2005;31:386-97.

2. Gilbody S, Bower P, Fletcher J, Richards D, Sutton AJ. Collaborative care for depression: a cumulative meta-analysis and review of longerterm outcomes. Arch Intern Med 2006;166:2314-21.

3. Williams JW, Jr., Gerrity M, Holsinger T, Dobscha S, Gaynes B, Dietrich A. Systematic review of multifaceted interventions to improve depression care. Gen Hosp Psychiatry 2007;29:91-116.

4. Glied S, Herzog K, Frank R. Review: the net benefits of depression management in primary care. Med Care Res Rev 2010;67:251-74.

5. Alexopoulos GS, Reynolds CF, Bruce ML, et al. Reducing suicidal ideation and depression in older primary care patients: 24-month outcomes of the PROSPECT study. Am J Psychiatry 2009; 166:882-90.

6. Klinkman MS, Bauroth S, Fedewa S, et al. Long-term clinical outcomes of care management for chronically depressed primary care patients: a report from the depression in primary care project. Ann Fam Med 2010;8:387-96.

7. Unutzer J, Katon WJ, Fan MY, et al. Long-term cost effects of collaborative care for late-life depression. Am J Manag Care 2008; 14:95-100.

8. Katon WJ, Seelig M. Population-based care of depression: team care approaches to improving outcomes. J Occup Environ Med 2008;50:45967.

9. Thota AB, Sipe TA, Byard GJ, et al. Collaborative care to improve the management of depressive disorders: a community guide systematic review and meta-analysis. Am J Prev Med 2012;42:525-38.

10. Reiss-Brennan B, Briot PC, Savitz LA, Cannon W, Staheli R. Cost and quality impact of Intermountain's mental health integration program. J Healthc Manag 2010;55:97-113.

11. Rubenstein LV, Chaney EF, Ober S, et al. Using evidence-based quality improvement methods for translating depression collaborative care research into practice. Fam Syst Health 2010;28:91-113.

12. Korsen N, Pietruszewski $\mathbf{P}$. Translating evidence to practice: Two stories from the field. J Clin Psychol Med Settings 2009;16:47-57.

13. Solberg LI, Glasgow RE, Unutzer J, et al. Partnership research: A practical trial design for evaluation of a natural experiment to improve depression care. Med Care 2010;48:576-82.

14. Unutzer J, Chan YF, Hafer E, et al. Quality improvement with pay-forperformance incentives in integrated behavioral health care. Am J Public Health 2012;102:e41-5.

15. Solberg LI, Crain AL, Maciosek MV, et al. A stepped-wedge evaluation of an initiative to spread the collaborative care model for depression in primary care. Ann Fam Med 2015;13:412-20.

16. Smith JL, Williams JW, Jr., Owen RR, Rubenstein LV, Chaney E. Developing a national dissemination plan for collaborative care for depression: QUERI Series. Implement Sci 2008;3:59.

17. Unutzer J, Katon W, Callahan CM, et al. Collaborative care management of late-life depression in the primary care setting: A randomized controlled trial. JAMA. 2002;288:2836-2845.

18. Coleman KJ, Magnan S, Neely C, Solberg L, Beck A, Trevis J, Heim C, Williams M, Katzelnick D, Unützer J, Pollock B, Hafer E, Ferguson R, Williams $\mathbf{S}$. The COMPASS initiative: description of a nationwide collaborative approach to the care of patients with depression and diabetes and/or cardiovascular disease. Gen Hosp Psychiatry 2017;44:69-76.

19. Rossom RC, Solberg LI, Magnan S, Crain AL, Beck A, Coleman KJ, Katzelnick D, Williams MD, Neely C, Ohnsorg $\mathbf{K}$, Whitebird $\mathbf{R}$, Brandenfels E, Pollock B, Ferguson R, Williams S, Unützer J. Impact of a national collaborative care initiative for patients with depression and diabetes or cardiovascular disease. Gen Hosp Psychiatry 2017;44:77-85.

20. Centers for Medicare and Medicaid. Healthcare Innovation Awards. https://innovation.cms.gov/initiatives/Health-Care-Innovation-Awards / . Accessed on 9/3/19.

21. Beck A, Boggs JM, Alem A, Coleman KJ, Rossom RC, Neely C, Williams MD, Ferguson R, Solberg LI. Large-Scale Implementation of Collaborative Care Management for Depression and Diabetes and/or Cardiovascular Disease. J Am Board Fam Med 2018;31:702-711.

22. Bion J, Richardson A, Hibbert P, Beer J, Abrusci T, McCutcheon M, et al. 'Matching Michigan': a 2-year stepped interventional programme to minimise central venous catheter-blood stream infections in intensive care units in England. BMJ Qual Saf 2013;22:110-23.

23. Dixon-Woods M, Leslie M, Tarrant $\mathbf{C}$ and Bion $\mathbf{J}$. Explaining Matching Michigan: an ethnographic study of a patient safety program. Implement Sci 2013;8:70.

24. Pronovost P, Needham D, Berenholtz S, Sinopoli D, Chu H, Cosgrove $\mathbf{S}$, et al. An intervention to decrease catheter-related bloodstream infections in the ICU. N Engl J Med 2006;355:2725-32.

25. Pronovost PJ, Goeschel CA, Colantuoni E, Watson S, Lubomski LH, Berenholtz SM, et al. Sustaining reductions in catheter related bloodstream infections in Michigan intensive care units: observational study. BMJ 2010;340:c309.

26. National Committee for Quality Assurance (NCQA). HEDIS Depression Measures Specified for Electronic Clinical Data Systems. https://www. ncqa.org/hedis/the-future-of-hedis/hedis-depression-measures-specified-for-electronic-clinical-data/. Accessed on 9/3/2019.

27. Kroenke K, Spitzer RL, Williams JBW. The PHQ-9: Validity of a brief depression severity measure. J Gen Intern Med 2001;16:606-613.

28. Stetler CB, Mittman BS, Francis $\mathbf{J}$ : Overview of the VA Quality Enhancement Research Initiative (QUERI) and QUERI theme articles: QUERI Series. Implement Sci 2008;3:8.

29. Stetler CB, McQueen L, Demakis J, Mittman BS: An organizational framework and strategic implementation for system-level change to enhance research-based practice: QUERI Series. Implement Sci 2008;3:30.

30. Berwick DM: A primer on leading the improvement of systems. BMJ. 1996;312:619-622.

31. Langley GJ, Moen R, Nolan KM, Nolan TW, Norman CL, Provost LP: The Improvement Guide: A Practical Approach to Enhancing Organizational Performance. 2nd edition. San Francisco: Jossey-Bass; 2009.

32. Damschroder LJ, Aron DC, Keith RE, Kirsh SR, Alexander JA, Lowery JC. Fostering implementation of health services research findings into practice: A consolidated framework for advancing implementation science. Implement Sci 2009;4:50-65.

33. University of Nebraska Medical Center. "SIG-E-CAPS". https://www. unmc.edu/media/intmed/geriatrics/reynolds/pearlcards/depression/ sigecaps.htm. Accessed on 9/3/2019.

34. National Institute for Care and Health Excellence (NICE). Depression in Adults: Recognition and Management. https://www.nice.org.uk/guidance/CG90/uptake. Accessed on 9/3/2019.

35. Eack SM, Greeno CG, Bong-Jae L. Limitations of the patient health questionnaire in identifying anxiety and depression: Many cases are undetected. Res Soc Work Pract 2006; 16:625-631.

Publisher's Note: Springer Nature remains neutral with regard to jurisdictional claims in published maps and institutional affiliations. 